\title{
Erratum: Extent of alcohol use and mental health (depressive and posttraumatic stress disorder symptoms) in undergraduate university students from 26 low-, middle- and high-income countries
}

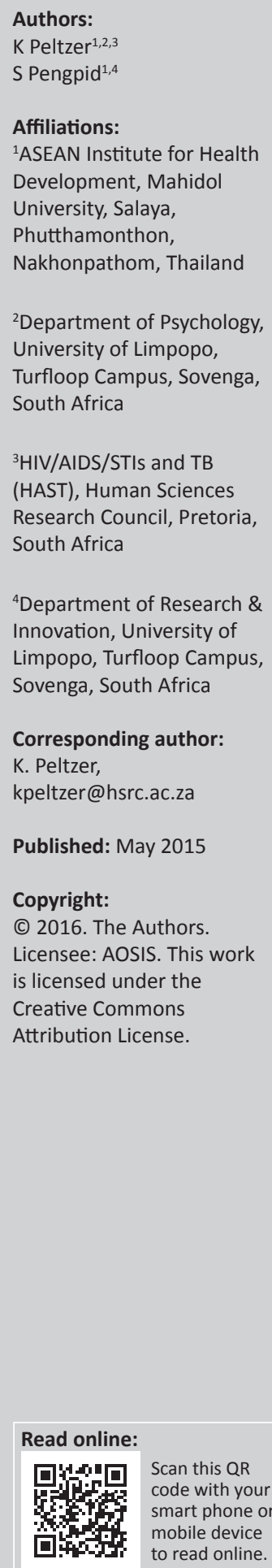

This article was erroneously published in 2015 under the DOI citation S Afr J Psychiatr 2015;22(2) instead of the correct S Afr J Psychiatr 2015;21(2). 